\title{
CADMIUM INDUCED APOPTOSIS AND CELLULAR TOXICITY IN RATS MAJOR SALIVARY GLANDS
}

\author{
Laila E Amin*, Walid Zedan**, Mazen T. Abou Elkhier* and Noha T. Abou El-Khier***
}

\begin{abstract}
Cadmium (Cd) is a heavy metal in the environment and contaminated food causes a serious risk to biodiversity and human health. $\mathrm{Cd}$ affects Cell proliferation, differentiation, and apoptotic pathway. A growing attention is now towards the severely damaging effects of $\mathrm{Cd}$ and its relation to different cancers. Unfortunately, few reports found about $\mathrm{Cd}$ effects on salivary tissues. In our study, we will investigate the effect of $\mathrm{Cd}$ on Rats major salivary glands and the level of Caspase 3 in their blood. Fourteen albino Rats were allotted randomly into 2 equal groups, control group I and group II which received $\mathrm{Cd}$ orally by gavage needle for 24 days. Parotid and submandibular salivary glands were carefully dissected and blood samples were collected from Rats. Paraffin blocks of the salivary glands were prepared and stained with Haematoxyline and Eosin (H\&E) stain, examined by light microscope examination. Caspase 3 levels were measured in the sera of Rats by enzyme immunoassay (EIA) using Rat Caspase 3 ELISA kit. Cd treated group revealed especially in the parotid glands more than submandibular glands a sever hydropic degeneration with areas of necrosis containing apoptotic cells (cellular toxicity). The serous acini appeared with loss of its acinar outlines, multiple intracellular vacuoles with compressed pyknotic nuclei. Additionally, few signs of cellular atypia appear. Our ELISA test results of Caspase 3 confirmed the apoptosis induction in $\mathrm{Cd}$ treated group with a high significant difference among the control group. In conclusion, our results revealed that $\mathrm{Cd}$ induces apoptosis and cellular toxicity in Rats major salivary tissues indicating that exposure to $\mathrm{Cd}$ in the environment and food is quite harmful. Our results shed a light on $\mathrm{Cd}$ which can be used with other heavy metal complexes as an antitumor drug in an optimized dosage.
\end{abstract}

\section{INTRODUCTION}

Heavy metals in the aquatic environment cause a serious risk to biodiversity and human health.Among heavy metals dispersed in the environment, Lead,
Mercury, Arsenic and Cadmium (Cd) are universal and have harshly damaging effects ${ }^{1}$. According to worldwide request for $\mathrm{Cd}$, approximately 30,000 tons of $\mathrm{Cd}$ is on the rampage into the environment

* Oral Biology Department, Faculty of Dentistry, Mansoura University.

** Oral Pathology Department, Faculty of Dentistry, Mansoura University.

*** Medical Microbiology \& Immunology Department, Faculty of Medicine, Mansoura University. 
each year. This heavy metal is not degraded in the environment, which escalates the risk of human exposure ${ }^{2}$. Cd will consistently be present in our society, either in beneficial products in the form of nickel-cadmium batteries, dyes, plastics, electrochemistry, paint pigments or in controlled wastes as a major source of pollution, in water and as a component of food material ${ }^{3,4}$. Cd is a widespread heavy metal which enters the biological systems from natural sources, such as volcanic emissions, weathering of rocks, mining processes as well as from industrial applications, agricultural practices and human usages ${ }^{5}$.

Cd emissions into the environment are normally continuous between the three main environmental compartments, air, water and soil. The majority of $\mathrm{Cd}$ exposure arises from ingestion of food substances due to uptake of $\mathrm{Cd}$ by plants from fertilizers, sewage, sludge, manure and atmospheric deposition ${ }^{6}$. Chronic exposure to low-level cadmium is associated with a number of health outcomes, such as end-stage renal failure, early onset of diabetes, renal complications, osteoporosis, disrupted blood pressure regulation, and increased cancer risk ${ }^{7-10}$. Very recently Cd contaminated rice fields in Mae Sot District, Tak Province, Thailand was reported by Songprasert et al. $2015^{11}$. Clinical and epidemiological data have shown that $\mathrm{Cd}$ exerts toxic effects not only on the kidneys, liver, lung and testis but also on the central nervous system $(\mathrm{CNS})^{12}$.

Programed cell death which called apoptosis is a physiological cell suicide program prominently involving the mitochondria ${ }^{13}$. Caspases play an important role in apoptotic mitochondrial damage, where aspartic acid specific protease, caspase- 9 , is the initiator ${ }^{14}$. Apoptosis is characterized by distinct morphological characteristics, such as cell shrinkage and convolution, pyknosis and karyorrhexis, intact cell membrane, lack of inflammation and finally, the breakdown of the cell into apoptotic bodies followed by secondary necrosis. Pro-caspase-9 cleavage generates its active form that further triggers effector Caspases ${ }^{15}$. Activated Caspase cascade culminates in altered apoptotic phenotypes, of which nuclear fragmentation is a major one ${ }^{16}$. Caspase- 3 is a regularly activated death protease, catalyzing the specific cleavage of many key cellular proteins ${ }^{17}$. Therefore, caspase- 3 is important for definite processes related to the disassembling of the cell and the formation of apoptotic bodies, but it may also function before or at the stage when commitment to loss of cell viability is made ${ }^{18}$.

Apoptosis is recognized as an early cellular indicator of toxicity ${ }^{15}$. Oxidative stress usually occurs in cells exposed to $\mathrm{Cd}$, and may overcome antioxidative defense systems, leading to cellular dysfunction ${ }^{16}$. Reactive oxygen species (ROS), an important indicator of oxidative stress, can occur in response to $\mathrm{Cd}$ exposure, resulting in damage to critical organelles, especially the mitochondria, eventually leading to apoptosis or necrosis ${ }^{19,20}$. Superoxide dismutase (SOD), catalase, and glutathione peroxidase and reductase (GR) are the major cellular defenses against ROS ${ }^{21}$. Accordingly, the relationship between redox homeostasis and apoptotic mechanisms of $\mathrm{Cd}$-induced toxicity needs further investigation. Studies have strongly suggested that oxidative mechanisms and Caspases initiated and executed Cd-induced apoptosis ${ }^{14,22,23}$.

Appropriately, few reports found about $\mathrm{Cd}$ effects on salivary tissues. Those which done on Rats indicated that $\mathrm{Cd}$ causes morphological and functional changes in Rat salivary glands ${ }^{24,25}$. The role of apoptosis induction on the salivary tissues and its confirmation is still deficient.

In our study, we will investigate experimentally the effect of $\mathrm{Cd}$ on Rats major salivary glands. Furthermore, the level of Caspase 3 in these Rats blood will be measured to assess the apoptotic response to Cd uptake. 


\section{MATERIALS AND METHODS}

Fourteen male albino Rats (age: 8 to 10 weeks and about 150 to $180 \mathrm{~g}$ body weight) were obtained from Experimental Animal Center of Faculty of Medicine, Mansoura University. The Rats were maintained on the commercial soft diets and water regimens under standard temperature $\left(22-25^{\circ} \mathrm{C}\right)$, ventilation and hygienic conditions. After one week of acclimatization, the Rats were allotted randomly into 2 equal groups.

\section{Grouping of animals and treatment}

The animals were randomly divided into two groups of 7 animals each, control group (I) and cadmium chloride group (II), both groups were given a standard Rat chow and water. Rats in Cd group were given treatments orally by gavage needle for 24 days. The dose was daily $2 \mathrm{ml}$ dose of a solution containing $10 \mathrm{mg} / \mathrm{kg}$ body weight of monohydrated cadmium chloride orally ${ }^{26}$. The cadmium chloride $(\mathrm{CdCl} 2)$ used in this study was obtained from Sigma Chemical Company (St. Louis, MO, USA)with the following specifications: hydrate minimum 98\%, water content approximately 2.5 mole/mole).

\section{ELISA test}

At the end of the experimental period, blood samples were collected from the retro-orbital venous plexus of each Rat. The blood samples were collected, left to clot at room temperature 1020 minutes, centrifuged at 2000-3000 rpm for 20 minutes, and then the serum was separated $\&$ stored at $-20^{\circ} \mathrm{C}$.

Caspase 3 levels were measured in the sera by enzyme immunoassay (EIA) for the in vitro quantitative measurement of Rat Caspase 3 (Sun Red Biological technology; Rat Caspase 3 ELISA kit) according to the manufacturer instructions.

\section{Haematoxyline and Eosin examination}

Animals of each group were sacrificed by exposure to ether anesthesia. Parotid and submandibular salivary glands were carefully dissected and fixed in 10\% formal saline. Paraffin blocks were prepared and $5 \mu$ sections were stained using regular Haematoxyline and Eosin (H\&E) stain procedures, and then processed for light microscope examination.

\section{Statistical analysis of ELISA test results}

Data from ELISA tests were tabulated, coded then analyzed using the computer program SPSS (Statistical package for social science) version 17.0. Descriptive statistics were calculated in the form of mean \pm Standard deviation (SD) and Student's t-test for the Caspase 3 Eliza results.

\section{RESULTS}

Clinical observations were as follow, three Rats were excluded from group (II) during our study, and one Rat died after first week of Cd uptake. A further two Rats died after three weeks of Cd induction. Finally, two Rats had a big abscess in their neck. All these Rats were compensated by others.

\section{H\&E results of Control group (I)}

The parotid gland showed the lobular pattern of the gland, the serous acini appeared densely packed with large basally located nuclei, intralobular ducts and surrounding connective tissue capsule fig A $(1,2)$.

The submandibular gland of control group showed the normal histological appearance of mixed acini, densely packed small serous acini, large mucous acini with compressed flat nucleus and multiple granular convoluted tubules fig A $(3,4)$.

\section{H\&E results of Cadmium chloride group (II)}

The parotid glands of cadmium treated group showed sever hydropic degeneration with areas of necrosis. The serous acini appeared with loss of its acinar outlines, multiple intracellular vacuoles with compressed pyknotic nuclei, areas of necrosis fig B $(1,2)$. 
The submandibular gland revealed less pathological changes in forms of atrophy in the shape of some serous acini with variable degree of cytoplasmic vacuolization and fusion of granular convoluted ducts fig B $(3,4)$.

Finally, areas of necrosis which contains apoptotic

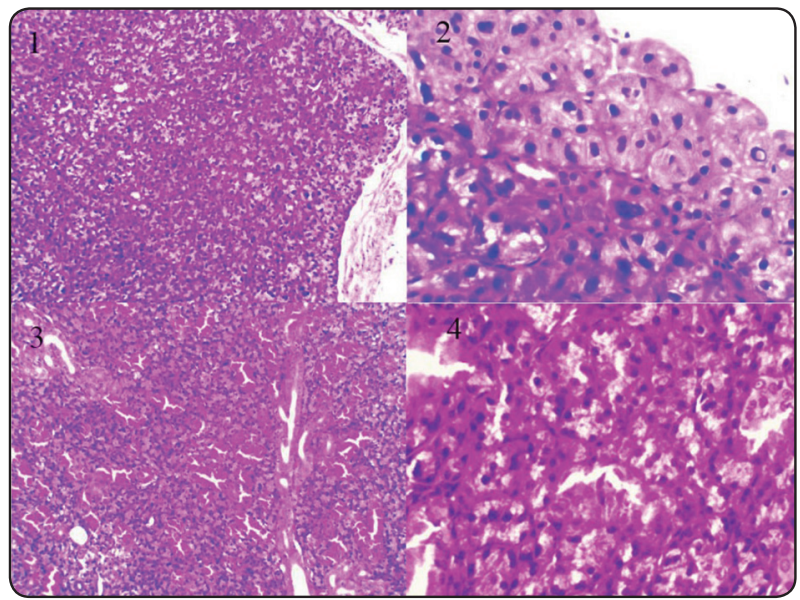

Fig. (A) $(1,2)$ photomicrograph of parotid gland of control group showing the lobular pattern of the gland with densely packed serous acini and basally located nuclei, intralobular ducts and surrounding connective tissue capsule. $(3,4)$ submandibular gland of control group showing the normal histological appearance of serous acini, striated duct, granular convoluted tubules, excretory duct and connective tissue septa (H\&E stain, $\mathrm{x} 100, \mathrm{x} 400)$.

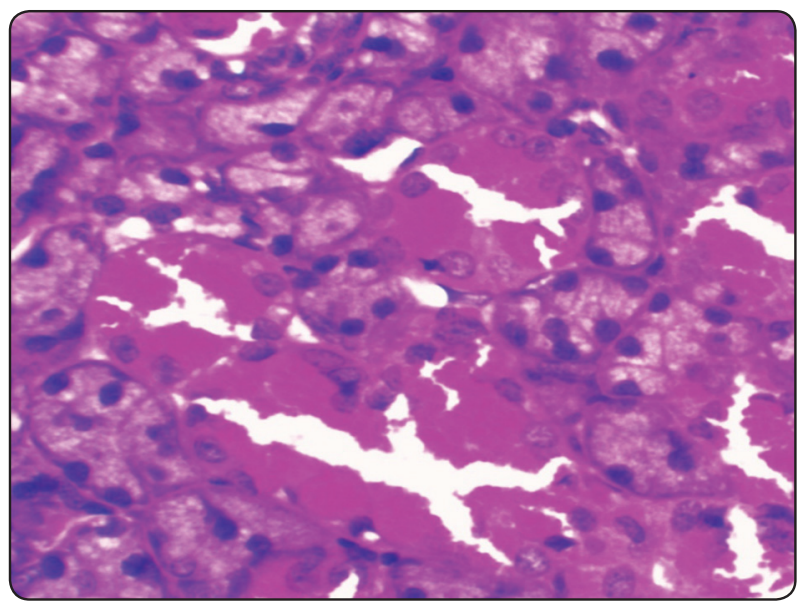

Fig. (C) Photomicrograph showed acinar cells in Cd treated group with areas of necrosis which contains apoptotic cells with nuclear fragmentations (pyknosis and karyorrhexis) and few signs of atypia appears as hyperchromatism, polymorphism, abnormal mitotic figures and some nuclei's is vesicular (H\&E stain, $\mathrm{x} 400$ ). cells with nuclear fragmentations (pyknosis and karyorrhexis) were obvious (figure C). Finally, few tissues of the parotid glands showed acinar cells in Cd treated group with some signs of atypia as hyperchromatism, polymorphism, abnormal mitotic figures and some nuclei's is vesicular (figure C)

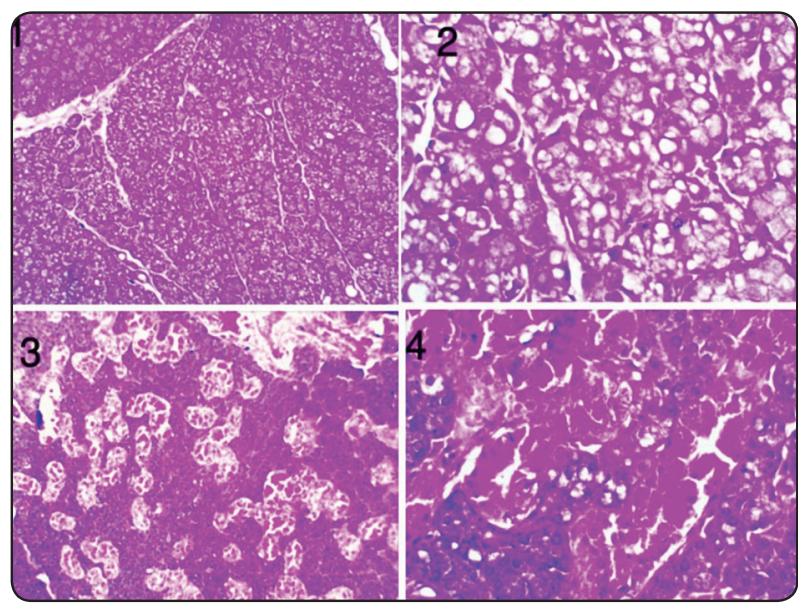

Fig. (B) $(1,2)$ photomicrograph the parotid gland of cadmium treated group showing separation of lobules with increased connective tissue septa in between, sever hydropic degeneration with massive atrophy of serous acini and large numbers of vacuoles with pyknotic nuclei, some areas of necrosis $(3,4)$ submandibular gland of cadmium treated group showing some areas of necrosis, atrophy in the shape of some serous acini with variable degree of cytoplasmic vacuolization and fusion of granular convoluted ducts (H\&E stain, x100, x400).

\section{Results of Caspase 3 ELISA test of Rats blood}

In the statistical comparison between the different groups, the significance of difference was tested using Student's t-test (Paired) to compare between mean of two related groups of numerical (parametric) data. There was a different Caspase 3 level in the blood of both groups. In the control group the mean \pm standard deviation sera level of caspase3 showed (1.93 .19); while in the cadmium group was (2.66 \pm .28$)$ and there was a high significant difference between the two groups (figure D, Table 1). 
TABLE (1) Caspase 3 ELISA test of Rats blood results

\begin{tabular}{|c|c|c|c|c|}
\hline & \multicolumn{2}{|c|}{ Groups } & \multirow[b]{2}{*}{ "P value } \\
\hline & & $\begin{array}{l}\text { Control } \\
\text { group }\end{array}$ & $\begin{array}{c}\mathrm{Cd} \\
\text { group }\end{array}$ & \\
\hline \multirow{4}{*}{ 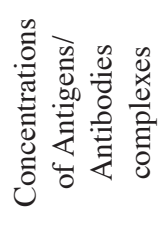 } & Mean & 1.93 & 2.66 & \multirow{4}{*}{$* * *<0.001$} \\
\hline & ${ }^{* *} \pm \mathrm{SD}$ & .19 & .28 & \\
\hline & Minimum & 1.63 & 2.16 & \\
\hline & Maximum & 2.20 & 3.09 & \\
\hline
\end{tabular}

"P value represents significance difference between control and cadmium groups

**All results are expressed as mean \pm standard deviation (SD).

*** Significant: at $P<0.05$, Non-significant: at $P>0.05$.

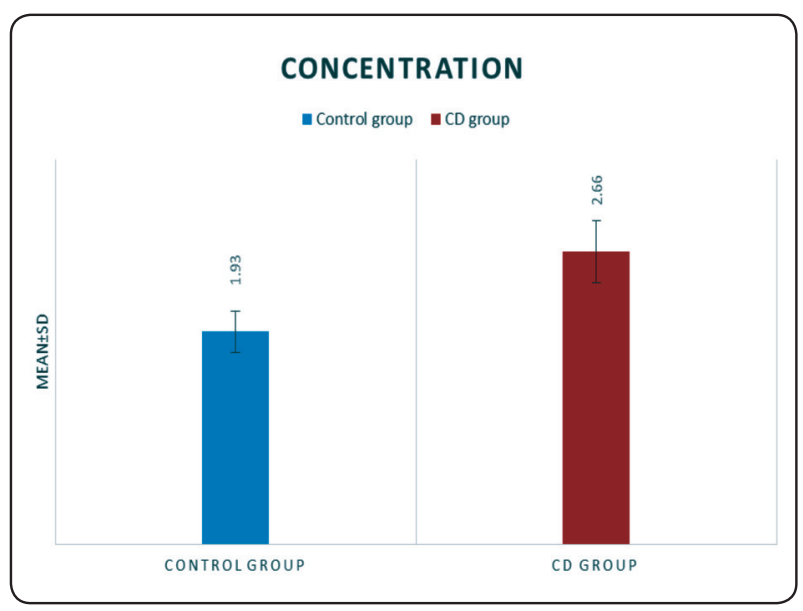

Fig. (D) Bar graph showing significant difference between control and cadmium group among Caspase 3 ELISA test results.

\section{DISCUSSION}

Current studies had shown that $\mathrm{Cd}$ affects Cell proliferation and differentiation, and demonstrated that $\mathrm{Cd}$ can cause cell apoptosis ${ }^{14,27}$. Cd indorses an early oxidative stress and subsequently contributes to the development of serious pathological conditions, as results of its long retention in some tissues ${ }^{28}$. A growing and recent reports are now been draw the world attention towards the severely damaging effects of $\mathrm{Cd}$ and its presence in our environment and contaminated food ${ }^{1,3,4,11}$.
In general, the present results in this study have shown that $\mathrm{Cd}$ treated group revealed a sever hydropic degeneration with areas of necrosis containing apoptotic cells (cellular toxicity) especially in the parotid glands more than submandibular glands. The serous acini appeared with loss of its acinar outlines, multiple intracellular vacuoles with compressed pyknotic nuclei. In accordance with our results an earlier research indicated that $\mathrm{Cd}$ caused morphological and functional changes in Rat salivary glands. Additionally, it was concluded that the extent of tubular and acinar damage equals the degree of gland dysfunction ${ }^{24,25}$. Furthermore, our results indicated that $\mathrm{Cd}$ induced apoptotic mechanisms this is in accordance with the results of Zhao et al. 2015, as they investigated the effects of $\mathrm{Cd}$ on osteoblasts in Rats the results of their study clarified that $\mathrm{Cd}$ has direct cytotoxic effects on osteoblasts, which are mediated by Caspases and mitogen-activated protein kinase (MAPK) pathways in Cd-induced apoptosis of osteoblasts ${ }^{29}$.

Our ELISA test results of the Rats blood of Caspase confirmed the apoptosis induction in $\mathrm{Cd}$ treated group with a high significant difference among the control group. Induction of Caspase 3 have been reported by Shih et al. 2004 indicated that $\mathrm{Cd}$ induced Caspase-independent apoptosis through a mitochondria- reactive oxygen species pathway ${ }^{30}$. Another affirmed results explaining that Cd-induced apoptosis was thought to be mediated by at least two pathways; Caspase-dependent Bid cleavage, and calpain-mediated mitochondrial Bax cleavage ${ }^{31}$. Continuously, another explanation by Permentar et al. 2011, studying the effects of heavy metals (nickel, chromium, or $\mathrm{Cd}$ ) on Rats liver derived cell lines they suggested that $\mathrm{Cd}$ agitated genes related to endoplasmic reticulum stress and raised the unfolded protein response leading to apoptosis ${ }^{32}$.

Furthermore, from our results Cd caused few cellular typia which may be a sign of carcinogenesis and might be these signs were exaggerated if the 
Cd dosage was higher and its exposure time was longer. Supportive to our hypothesis, recently Nawrot et al. 2015 stated that "there are an epidemiological evidence of the last decade steadily identifies low-level environmental exposure to cadmium as a risk factor for total cancer and lung cancer"33. Interestingly, Sherief et al. 2015, they investigated $\mathrm{Cd}$ status among pediatric cancer patients in Egypt and concluded that there is a positive association between $\mathrm{Cd}$ exposure and pediatric malignancy ${ }^{34}$. Contrary, Eriksen et al. 2015 did not find an association between dietary cadmium intake and prostate cancer risk in a cohort of Danish men ${ }^{35}$.

Finally, in an astonishing findings a research done by $\mathrm{He}$ et al. 2015, they affirmed the induction of apoptosis by $\mathrm{Cd}$ with other heavy metals on glioma tumors and the availability to use an optimized mixture of heavy metals as an antitumor drug to induce glioma cell toxicity ${ }^{36}$. Moreover, another research have been done by Zhang et al. 2015 their results suggested that L-Ornithine Schiff base-copper and $\mathrm{Cd}$ complexes have proteasomeinhibitory capabilities and have the potential to be developed into novel anticancer drugs ${ }^{37}$. Earlier study suggested that $\mathrm{Cd}$ organic complexes are capable of inhibiting tumor cellular proteasome activity and consequently induce cancer cell-specific apoptotic death. These results start a new era of the usage an optimized dosage of $\mathrm{Cd}$ and other heavy metals as therapeutic antitumor drugs ${ }^{38}$.

In conclusion, our results revealed that $\mathrm{Cd}$ induces apoptosis and cellular toxicity in the salivary tissues of the tested group with a significant increase in the Caspase 3 level in Rats blood. The previous results affirmed that the gradual increase of exposure to $\mathrm{Cd}$ in the environment and food is quite harmful. It is recommended that advanced epidemiological and environmental studies should be done on the harmful effects of $\mathrm{Cd}$. On the other hand the affirmed induction of apoptosis by $\mathrm{Cd}$ can be used with other heavy metal complexes as an antitumor drug in an optimized dosage. Further researches on the last point are recommended with a more experimental and clinical trials on different cancers to open a new hope to a new antitumor therapy.

\section{REFERENCE}

1. Diawara MM, Litt JS, Unis D, Alfonso N, Martinez L, Crock JG, et al. Arsenic, cadmium, lead, and mercury in surface soils, Pueblo, Colorado: implications for population health risk. Environ Geochem Health. 2006; 28(4):297-315.

2. Agency for Toxic Substance and Disease Registry (ATSDR). Toxicological profile for Cadmium. Department of Health and Human Services, Public Health Service (US). Atlanta, 2005.

3. Ikeda M, Zang ZW, Moon CS, Shimbo S, Watanabe T, Nakatsuka H, Matsuddalnoguchi N, Higashikawa K. Possible effects of environmental cadmium exposure on kidney function in the Japanese general population. Int. Arch. Occup. Environ. Health. 2000; 73:15-25.

4. Jarup L, Alfven T, Persson B, Toss G, Elinder CG. Cadmium may be a risk factor for osteoporosis. Occup. Environ. Med. 1998; 55:435439.

5. Anderson O, Nielsen JB, Svendsen E. Oral cadmium chloride intoxication in mice: Effects of dose on tissue damage, intestinal absorption and relative organ distribution. Toxicology. 1988; 48:225-236.

6. Hotz P, Buchet JP, Bernard A, Lison D, Lauwerys R. Renal effects of low-level environmental cadmium exposure: 5-year followup of a subcohort from the Cadmibel Study. Lancet. 1989; 354:1508.

7. Lauwerys R, Bernard A, Buchet JP. Does environmental exposure to cadmium represent a health risk? Conclusions from the Cadmibel Study. Acta Clin. Belg. 1991; 46:219-225.

8. Iwata K, Saito H, Moryiama M, Nakano A. Follow up study of renal tubular dysfunction and mortality in residents of an area polluted with cadmium. Br. J. Ind. Med. 1992; 49:736-737.

9. Bernard A, Lauwery R, Amor AO. Loss of glomerular polyanion correlated with albuminuria in experimental cadmium nephropathy. Arch. Pathol. 1992; 66:272-278.

10. Nawrot, T.; Plusquin, M.; Hogervorst, J.; Roels, H.A.; Celis, H.; Thijs, L.; Vangronsveld, J.; Hecke, E.V.; 
Staessen, J.A. Environmental exposure to cadmium and risk of cancer: A prospective population-based study. Lancet Oncol. 2006; 7, 119-126.

11. Songprasert N, Sukaew T, Kusreesakul K, Swaddiwudhipong W, Padungtod C, Bundhamcharoen K. Additional Burden of Diseases Associated with Cadmium Exposure: A Case Study of Cadmium Contaminated Rice Fields in Mae Sot District, Tak Province, Thailand. Int J Environ Res Public Health. 2015; 7;12(8):9199-217.

12. Xu C, Zhang H, Liu C, Zhu Y, Wang X, Gao W, Huang S, Chen L. Rapamycin inhibits Erk1/2-mediated neuronal apoptosis caused by cadmium. Oncotarget. 2015; 28;6(25):21452-67

13. Bossy-Wetzel E, Green DR. Apoptosis: checkpoint at the mitochondrial frontier. Mutat Res. 1999; 434:243-251.

14. Mao W.P., Ye J.L., Guan Z.B., Zhao J.M., Zhang C., Zhang N.N., Jiang P., Tian T. Cadmium induces apoptosis in human embryonic kidney (HEK) 293 cells by Caspase-dependent and -independent pathways acting on mitochondria. Toxicol. In Vitro. 2007; 21:343-354.

15. Weber LP, Kiparissis Y, Hwang GS, Niimi AJ, Janz DM, Metcalfe CD. Increased cellular apoptosis after chronic aqueous exposure to nonylphenol and quercetin in adult medaka (Oryzias latipes). Comp Biochem Physiol C Toxicol Pharmacol. 2002; 131, 51-59.

16. Cuypers A, Plusquin M, Remans T, Jozefczak M, Keunen E, Gielen H, Opdenakker K, Nair AR, Munters E, Artois TJ, Nawrot T, Vangronsveld J, Smeets K. Cadmium stress: an oxidative challenge. Biometals. 2010; 23, 927-940.

17. Vermeulen K, Van Bockstaele DR, Berneman ZN. Apoptosis: mechanisms and relevance in cancer. Ann. Hematol. 2005; 84(10):627-39.

18. Porter AG1, Jänicke RU. Emerging roles of caspase-3 in apoptosis. Cell Death Differ. 1999; 6 (2):99-104.

19. Pourahmad J, O’Brien PJ, Jokar F, Daraei B. Carcinogenic metal induced sites of reactive oxygen species formation in hepatocytes. Toxicol In Vitro. 2003; 17, 803-810.

20. Thijssen S, Cuypers A, Maringwa J, Smeets K, Horemans N, Lambrichts I, Van Kerkhove E. Low cadmium exposure triggers a biphasic oxidative stress response in mice kidneys. Toxicology. 2007; 236, 29-41.

21. Yamamoto T, Hsu S, Lewis J, Wataha J, Dickinson D, Singh B, Bollag WB, Lockwood P, Ueta E, Osaki T, Schuster G. Green tea polyphenol causes differential oxidative environments in tumor versus normal epithelial cells. J. Pharmacol. Exp. Ther. 2003; 307, 230-236.
22. Ikediobi CO, Badisa VL, Ayuk-Takem LT, Latinwo LM, West J. Response of antioxidant enzymes and redox metabolites to cadmium-induced oxidative stress in CRL-1439 normal Rat liver cells. Int J Mol Med. 2004; 14, 87-92.

23. Liu J, Qu W, Kadiiska MB. Role of oxidative stress in cadmium toxicity and carcinogenesis. Toxicol Appl Pharmacol. 2009; 238, 209-214.

24. Chiarenza A., Elverdin J.C., Espinal E., Giglio M.J. Effects of cadmium on the function and structure of the Rat salivary glands. Archives of Oral Biology. 1989; 34,12, 999-1002.

25. Abdollahi M, Dehpour A, Kazemian P. Alteration by cadmium of Rat submandibular gland secretory function and the role of the 1-arginine/nitric oxide pathway. Pharmacol Res. 2000; 42(6):591-7.

26. Attia A. M. M, Ibrahim Fatma A. A., Abd EL-Latif A N. and Aziz SW. Antioxidant effects of curcumin against cadmium chloride-induced oxidative stress in the blood of Rats. J. Pharmacognosy Phytother. 2014; 6(3), pp. 33-40.

27. Cadmium: cellular effects, modifications of biomolecules, modulation of DNA repair and genotoxic consequences (a review). Biochimie. 2006; 88, 1549-1559.

28. Bagchi D, Bagchi M, Stohs SJ, Ray SD, Kuszynski CA, Pruess HG. Free radicals and grape seed proathocyanidin extract: importance in human health and disease prevention. Toxicol. 2000; 148:187-197.

29. Zhao H, Liu W, Wang Y, Dai N, Gu J, Yuan Y, Liu X, Bian J, Liu ZP. Cadmium induces apoptosis in primary Rat osteoblasts through Caspase and mitogen-activated protein kinase pathways. J Vet Sci. 2015; 16(3):297-306.

30. Shih CM, Ko WC, Wu JS, Wei YH, Wang LF, Chang EE, Lo TY, Cheng HH, Chen CT. Mediating of Caspaseindependent apoptosis by cadmium through the mitochondria-ROS pathway in MRC-5 fibroblasts. J Cell Biochem. 2004; 1; 91(2):384-97.

31. Oh SH1, Lee BH, Lim SC. Cadmium induces apoptotic cell death in WI 38 cells via caspase-dependent Bid cleavage and calpain-mediated mitochondrial Bax cleavage by Bcl-2-independent pathway. Biochem. Pharmacol. 2004; 1;68(9):1845-55.

32. Permenter MG, Lewis JA, Jackson DA. Exposure to nickel, chromium, or cadmium causes distinct changes in the gene expression patterns of a Rat liver derived cell line. PLoS One. 2011; 6(11):e27730. doi: 10.1371/journal. pone. 0027730 .

33. Nawrot TS, Martens DS, Hara A, Plusquin M, Vangronsveld J, Roels HA, Staessen JA. Association of 
total cancer and lung cancer with environmental exposure to cadmium: the meta-analytical evidence. Cancer Causes Control. 2015; 26 (9):1281-8.

34. Sherief LM, Abdelkhalek ER, Gharieb AF, Sherbiny HS, Usef DM, Almalky MA, Kamal NM, Salama MA, Gohar W. Cadmium status among pediatric cancer patients in Egypt. Medicine (Baltimore). 2015; 94(20):e740. doi: 10.1097/MD.0000000000000740.

35. Eriksen KT, Halkjær J, Meliker JR, McElroy JA, Sørensen M, Tjønneland A, Raaschou-Nielsen O. Dietary cadmium intake and risk of prostate cancer: a Danish prospective cohort study. BMC Cancer. 2015; 26;15:177.
36. He W, Li Y, Tian J, Jiang N, Du B, Peng Y. Optimized mixture of $\mathrm{As}, \mathrm{Cd}$ and $\mathrm{Pb}$ induce mitochondria-mediated apoptosis in C6-glioma via astroglial activation, inflammation and P38-MAPK. Am. J. Cancer Res. 2015; 15;5(8):2396-408.

37. Zhang Z, Bi C, Fan Y, Zhang N, Deshmukh R, Yan X, Lv $X$, Zhang P, Zhang X, Dou QP. L-Ornithine Schiff basecopper and -cadmium complexes as new proteasome inhibitors and apoptosis inducers in human cancer cells. J Biol. Inorg. Chem. 2015; 20(1):109-21.

38. Zhang Z, Bi C, Buac D, Fan Y, Zhang X, Zuo J, Zhang P, Zhang N, Dong L, Dou QP. Organic cadmium complexes as proteasome inhibitors and apoptosis inducers in human breast cancer cells. J Inorg Biochem. 2013; 123:1-10. 